\title{
Incarcerated Gravid Uterus in a Neglected Incisional Hernia with Intrauterine Fetal Death
}

Shayee Kalyee Shanjeev P. B*, Joyce Prabakar J, Kannan R

Institute of General Surgery, Madras Medical College and Rajiv Gandhi Government General Hospital, Chennai, Tamilnadu, India

DOI: $\underline{10.36347 / \text { sasjs.2020.v06i02.002 }}$

| Received: 30.01 .2020 | Accepted: 06.02.2020 | Published: 09.02.2020

*Corresponding author: Shayee Kalyee Shanjeev. P. B

\section{Abstract}

Gravid uterus in an incisional hernia of the anterior abdominal wall is rare and a serious condition. Initially the hernia is reducible, but as pregnancy advances, it may be complicated. We report a case of 24 Yr old female Gravida 2 Para 1 in the 28th week of gestation who came to emergency department with history of swelling in the lower abdomen, pain for past 1 day with a negative cough impulse and absent foetal heart sound. On emergency exploration, gravid uterus was found to be the content, following which hysterotomy and anatomical repair were done.

Keywords: Incisional hernia, gravid uterus, hysterotomy.

Copyright @ 2020: This is an open-access article distributed under the terms of the Creative Commons Attribution license which permits unrestricted use, distribution, and reproduction in any medium for non-commercial use (NonCommercial, or CC-BY-NC) provided the original author and source are credited.

\section{INTRODUCTION}

A hernia is defined as a protrusion, bulge or projection of an organ or a part of an organ through the body wall that normally contains it [1]. Pregnancy associated with incisional hernia with whole of the gravid uterus as the content of the sac is a rare occurrence. The risks of both maternal and foetal complications are high. Herniation of gravid uterus is probably rare because of the fact that by the time the uterus reaches the level of hernial aperture, it is usually too large to enter the hernial sac. Less than 18 cases have been reported in literature. Because of the rare nature of the disease there has been no consensus in their management.

We report a case of neglected incisional hernia with gravid uterus as the content presenting in the third trimester with intrauterine foetal death.

\section{CASE REPORT}

24 Yr old female gravida 2 Para 1 in the $28^{\text {th }}$ week of gestation came to emergency department with history of swelling in the lower abdomen and pain, vomiting and inability to perceive fetal movements for past 1 day. Lower segment cesarean section was done 2 years ago following which the patient developed wound infection and required secondary suturing of the wound. On examination patient was conscious, oriented, dehydrated with tachycardia. A firm tender swelling of
$20 * 25 \mathrm{cms}$ was noted in the suprapubic region. Cough impulse was absent and fetal parts could be palpated. Old scar was seen in the skin overlying the swelling with sinuses at the both ends of the scar.

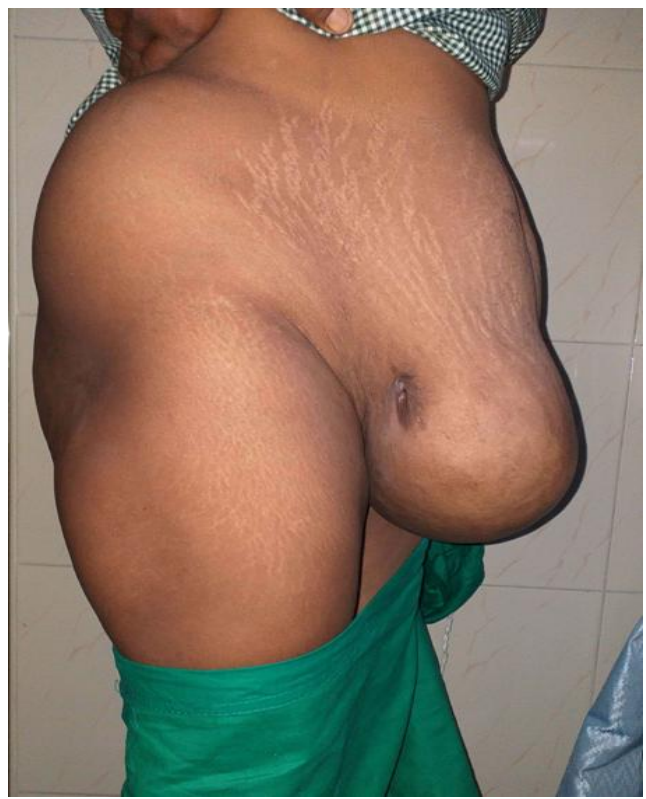

Fig-1: Preoperative picture of the patient is in standing position showing irreducible hernia bulge along with sinus at the end of the sinus 


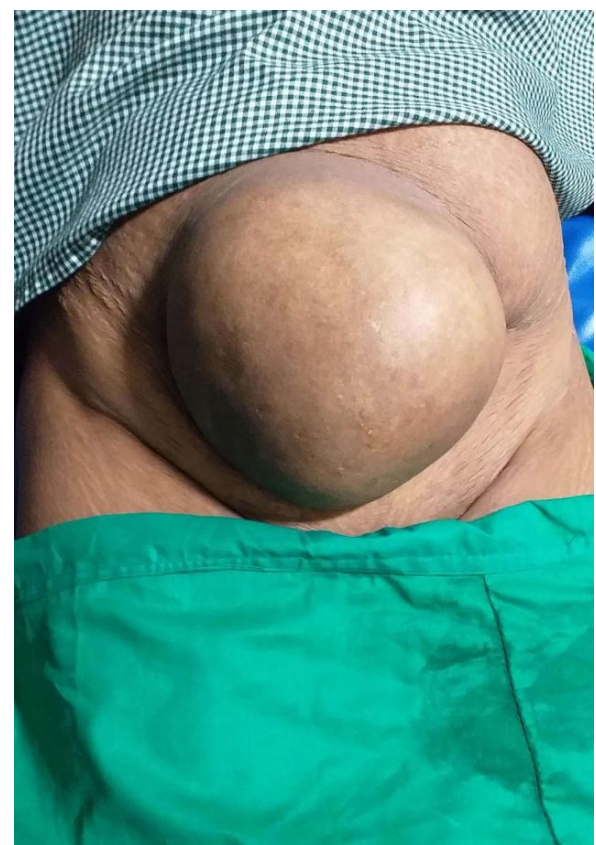

Fig-2: Preoperative picture of the patient is in supine position showing irreducible hernia bulge

Ultrasound revealed gravid uterus as the content and single fetus with absent fetal cardiac activity. Patient was resuscitation with IV fluids, antibiotics, analgesics and taken for surgical exploration. Transverse incision was made over the swelling and sac identified and dissected all around. Content was found to be gravid uterus. Rectus was found to be thinned out with a defect of $15^{*} 10 \mathrm{cms}$. Bowel and the rest of the abdominal viscera were found to be healthy.

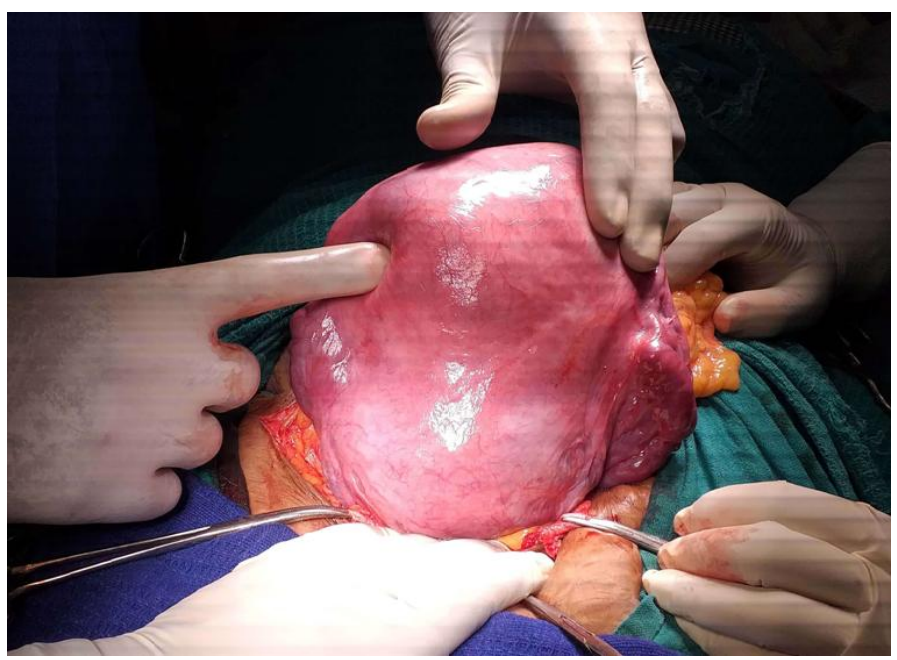

Fig-3: Intraoperative picture showing gravid uterus as the content

Hysterotomy was done followed by trimming of excess sac. Anatomical repair was done with 1-0 polypropylene continuous sutures without tension. Old scar and both the sinuses were excised and skin closed Postoperative period was uneventful. Patient was discharged on $5^{\text {th }}$ day POD. Regular follow up at 2 months revealed no complains.

\section{DISCUSSION}

Incisional hernia is an abdominal wall defect that occurs at the site of previous surgical incision following breakdown in the continuity of the fascial closure. Incidence is around $3.8-11.5 \%$. Around ninety percent occur within the first 36 months following surgery [2]. Most Common Surgery causing incisional hernia is LSCS. Risk factors include vertical midline incision, wound infection, malnutrition, poor surgical technique, additional operative procedure, presence of postoperative abdominal distension, intra- abdominal sepsis, residual intra abdominal abscess, wound dehiscence, postoperative fever, Smoking and Chronic cough. In our case post operative wound infection contributed to the development of the hernia.

Herniation of gravid uterus has been reported sporadically as incisional hernia and umbilical hernia of pregnancy. Cases with variable onset of herniation at 
gestation ranging from 4 to 8 months have been reported [3]. It is a serious obstetric situation and is associated with severe complications like intrauterine growth retardation, accidental hemorrhage, Preterm labour, Spontaneous abortion, Accidental hemorrhage, Dysfunctional labour, Obstructed labour intrauterine death, rupture of lower segment of uterus, and burst abdomen and avascular necrosis due to excessive stretching of skin $[4,5]$.

The diagnosis of gravid uterus in incisional hernia is made by presence of an unusual bulge of the abdomen with stretched thin skin, the easily palpable uterus and foetal parts. Imaging study with ultrasound assist in diagnosis and in detecting complications like IUGR, oligohydramnios but has limitations.

The management of these pregnant patients with incisional hernia poses a dilemma as no consensus approach has been described. The management therefore has to be individualised according to the patient, their gestational age, presence of complications and foetal status.

Uncomplicated incisional hernia can be managed conservatively with Bed rest, abdominal binders, Avoid straining, manual reduction of hernia, regular foetal monitoring, and physiotherapy of abdominal wall muscles during antenatal period and labour to allow the pregnancy to grow to term [8]. The therapeutic options include a caesarean section which offers a means of hernia repair during surgery, as opposed to vaginal birth which involves delayed repair [9]. However, given the uncertainties about the integrity of the anterior abdominal wall during labour especially in the case of an incisional hernia, elective caesarean section is considered by many as the safest mode of delivery [6]. Another advantage is that during these caesarean sections, concomitant herniorrhaphy can be carried out in the same sitting [7]. Nevertheless, elective postpartum herniorrhaphy is reported as the normal standard [7], the reason being that the overstretched abdominal wall may limit proper repair, and the associated risk of wound dehiscence and infection may be higher.

Complicated incisional hernia (Incarceration, burst abdomen, strangulation, and intrauterine foetal death) mandates immediate surgical exploration.

In our case, patient presented with an irreducible hernia with intrauterine foetal death and hence emergency exploration was done. Because of The presence of intrauterine dead fetus and the grossly stretched abdominal wall mesh repair was not done for fear of wound infection and dehiscence. Instead we proceeded with suture repair of the defect initially and planned for definitive meshplasty at a later date keeping the patient in regular follow up.

\section{CONCLUSION}

Although incisional hernia in antenatal period is not uncommon, the presence of gravid uterus in the sac is very rare. Management of patient with gravid uterus in incisional hernia needs to be individualized depending on the patient's everyday complaints and the gestational age. Diagnosis is based on the history, examination and ultrasound examination. Conservative management till term is recommended. Awareness of all complications and unusual presentation of complications and management can help to achieve successful pregnancy outcome.

\section{Conflict of interest: No}

\section{REFERENCES}

1. Dare FO, Makinde OO, Lawal OO. Gravid uterus in an anterior abdominal wall hernia of a Nigerian woman. International Journal of Gynecology \& Obstetrics. 1990 Aug;32(4):377-9.

2. Read RC, Yoder G. Recent trends in the management of incisional herniation. Archives of Surgery. 1989 Apr 1;124(4):485-8.

3. Ray KK, Aggarwal S, Banerjee K, Karan S, Charu C. Gravid uterus in an incisional hernia leading to burst abdomen. Internet $\mathbf{J}$ Gynecol Obstet. 2005;5:2-5.

4. Sahu L, Bupathy AJ. Evisceration of pregnant uterus through the incisional hernia site. Obstet Gynaecol Res. 2006 Jun; 32(3):338-40.

5. Dare FO, Makinde OO, Lawal OO. Gravid uterus in an anterior abdominal wall hernia of a Nigerian woman. Int J Gynaecol Obstet. 1990 Aug; 32(4):377-9.

6. Rao R, Shankaregowda H. A case of herniated gravid uterus through a laparotomy scar. Indian journal of medical sciences. 2006 Apr $1 ; 60(4): 154-7$.

7. Chaudhuri S, Mitra SN, Daga A, Bandopadhyay D. Gravid uterus in an anterior abdominal wall hernia and successful repair at the time of caesarean section. British Journal of Medical Practitioners. 2009 Dec 1;2(4): 57-58. 